\title{
Penerapan Algoritma Floyd Warshall pada Sistem Informasi Puskesmas Kabupaten Karanganyar
}

\author{
Retno Tri Vulandari ${ }^{*}$, Muhammad Hasbi $^{2}$, Bayu Tristanto ${ }^{3}$ \\ ${ }^{1,2,3}$ STMIK Sinar Nusantara Surakarta \\ *retnotv@sinus.ac.id
}

\begin{abstract}
ABSTRAK
Karanganyar adalah sebuah Kabupaten yang berada di Provinsi Jawa Tengah. Kabupaten Karanganyar mempunyai Pusat Kesehatan Tingkat Pertama yaitu 21 puskesmas yang tersebar di beberapa kelurahan untuk menjangkau masyarakat sebagai sarana kesehatan tingkat pertama. Masyarakat khususnya para pendatang baru yang belum mengetahui lokasi puskesmas di Kabupaten Karanganyar hal ini akan menjadi kendala, sebab luasnya wilayah, lalu lintas yang padat bagi yang belum hafal rute di daerah Kabupaten Karanganyar akan menimbulkan kebingungan untuk menentukan rute perjalanan menuju puskesmas karena tidak tersedia visualisasi tempat, jarak antara puskesmas yang akan dilalui. Maka akan dicari cara untuk membantu mencari lokasi puskesmas di Kabupaten Karanganyar supaya informasi yang di cari lebih cepat di dapat. Tujuan dari penelitian ini adalah untuk mempermudah menemukan dimana letak lokasi puskesmas itu berada dan mampu mempermudah dan memberi akses pada masyarakat yang membutuhkan pencarian lokasi puskesmas di Kabupaten Karanganyar. Metode penelitian yang digunakan dalam pembuatan sistem ini adalah algoritma Floyd-Warshall, dan membutuhkan data melalui pengambilan data dari Dinas Kesehatan Kabupaten Karanganyar dan observasi langsung mengunakan bantuan media internet serta implementasi ini menggunakan php, MySql server, web, domain dan hosting sebagai sarana pembuatan sistem. Hasil dari penelitian ini berupa rute terdekat yang terhubung dengan Map Google, yaitu informasi letak lokasi puskesmas dan node-node yang tersebar di Kabupaten Karanganyar yang dapat dimanfaatkan masyarakat dalam mencari lokasi puskesmas di Kabupaten Karanganyar.

Kata kunci: sistem informasi puskesmas, algoritma Floyd Warshall, rute terdekat.
\end{abstract}

\section{ABSTRACT}

The Community Health Center is one of the very important public health service facilities. For new residents, it is very important to have information about the location of the puskesmas or hospital as well as information about the shortest path to the puskesmas or hospital. The extent of the area and heavy traffic is an obstacle for those who do not have route information in Karanganyar Regency. The purpose of this study is to make it easy to the community find where the location of the health center community is and be able to facilitate access for many people who need to find the location of the health community center in Karanganyar Regency. The research method used in making this system is Floyd-Warshall and then requires data through data collection from the Karanganyar District Health Office. The results of this study are in the form of the closest route that is connected to Google Maps, which is information about the location of the health center in Karanganyar Regency which is beneficial for people outside Karanganyar Regency. The test results of this study using the Floyd Warshall whose results method further guarantee its success in determining the nearest route.

Keywords: Floyd-Warshall algorithm, geographic information systems, public health centers. 


\section{PENDAHULUAN}

Pusat Kesehatan Masyarakat yang selanjutnya disebut Puskesmas adalah fasilitas pelayanan kesehatan yang menyelenggarakan upaya kesehatan masyarakat dan upaya kesehatan perseorangan tingkat pertama, dengan lebih mengutamakan upaya promotif dan preventif, untuk mencapai derajat kesehatan masyarakat yang setinggi-tingginya di wilayah kerjanya (Bellina, 2017). Tujuan dari pelayanan kesehatan adalah untuk memenuhi kebutuhan individu atau masyarakat untuk mengatasi, menetralisasi atau menormalisasi semua masalah atau semua penyimpangan tentang kesehatan yang ada dalam masyarakat (Konli, 2014). Pentingnya rute terpendek puskesmas yaitu untuk mencari informasi rute rumah sakit dan puskesmas terdekat. Sehingga dapat membantu pendatang baru dalam mencari posisi dan rute rumah sakit maupun puskesmas terdekat agar pada saat mereka mengalami keadaan yang sangat genting orang tersebut segera mendapatkan pertolongan medis untuk memperkecil resiko yang tidak diinginkan (Anisiyah, Agus, \& Hamdani, 2011)

Berdasarkan uraian latar belakang tersebut maka dibuat sistem informasi geografis pemetaan yang bertugas menyampaikan informasi lokasi puskesmas beserta rute terpendek yang diperuntukkan untuk masyarakat pendatang baru di Kabupaten Karanganyar. Adanya sistem ini dapat memudahkan masyarakat khususnya pendatang baru menuju puskesmas terdekat.

\section{METODE}

\subsection{Algoritma Floyd-Warshall}

Algoritma Floyd-Warshall adalah sebuah algoritma untuk menentukan jarak terpendek antara semua pasang titik dalam suatu graf berarah berbobot (Daniel, Prida, \& Tadeo, 2019). Algoritma Floyd-Warshall digunakan untuk menentukan jarak terpendek antara semua pasang titik dalam suatu graf berbobot di mana titik-titiknya adalah $\mathrm{v}_{1}, \mathrm{v}_{2}, \ldots, \mathrm{v}_{\mathrm{n}}$, prosedurnya adalah sebagai berikut (Marsudi, 2016).

Langkah 1: Untuk $\mathrm{i}=1,2, \ldots, \mathrm{n}$, set $\mathrm{d}(\mathrm{i}, \mathrm{i})=0$, Untuk $\mathrm{i} \neq \mathrm{j}$, jika $\mathrm{v}_{\mathrm{i}} \mathrm{v}_{\mathrm{j}}$ sebuah sisi, $\mathrm{d}(\mathrm{i}, \mathrm{j})$ adalah bobot dari sisi ini; yang lain isi $\mathrm{d}(\mathrm{i}, \mathrm{j})=\infty$.

Langkah 2: Untuk $k=1,2, \ldots, n$, dan untuk $i, j=1,2, \ldots, n, j i k a v_{i} v_{j}$

$$
d(i, j)=\min \{d(i, j), d(i, k), d(k, j)\}
$$

Nilai akhir dari $d(i, j)$ adalah jarak terpendek dari $\mathrm{v}_{\mathrm{i}} \mathrm{ke} \mathrm{v}_{\mathrm{j}}$.

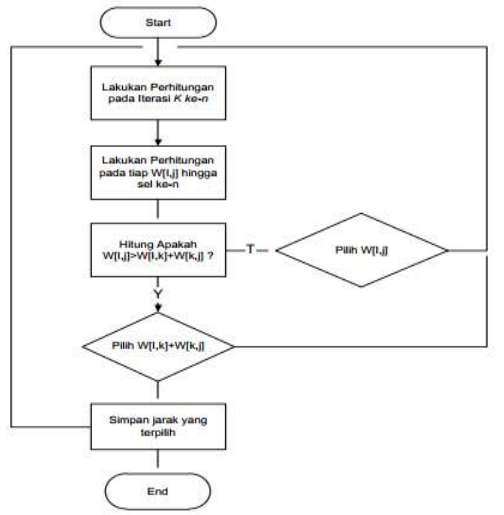

Gambar 1. Flowchart algoritma Floyd-Warshall (Darnita, Toyib, \& Rinaldi, 2017) 
Proses penentuan nilai minimum algoritma Floyd-Warshall menurut Gambar 1 dapat dijelaskan sebagai berikut.

a. Pada iterasi ke-1, setiap sel matriks dilakukan pengecekan apakah jarak antar dua titik mula mula lebih besar dari penjumlahan antar jarak titik asal ke titik tujuan (titik tujuan=iterasi ke-1) dengan jarak titik asal (titik asal=iterasi ke-1) ke titik tujuan. Dengan kata lain apakah $\mathrm{W}[\mathrm{i}, \mathrm{j}]>\mathrm{W}[\mathrm{i}, \mathrm{k}]+\mathrm{W}[\mathrm{k}, \mathrm{j}]$.

b. Jika iya, maka jarak antar dua titik mula mula diganti dengan penjumlahan antar jarak titik asal ke titik tujuan (titik tujuan = iterasi ke-1) dengan jarak titik asal (titik asal = iterasi ke1) ke titik tujuan $(\mathrm{W}[\mathrm{i}, \mathrm{k}]+\mathrm{W}[\mathrm{k}, \mathrm{j}])$.

c. Jika tidak, maka jarak yang digunakan yaitu jarak antar dua titik mula mula (W[i,j]).

d. Proses iterasi dilakukan hingga pada iterasi terakhir (jumlah iterasi $=$ jumlah total titik).

\subsection{Metode Pengumpulan Data}

a. Metode Wawancara

Metode ini dilakukan dengan cara tanya jawab langsung dengan Dinas Kesehatan Kabupaten Karanganyar mengenai jumlah puskesmas dan identitas tiap puskesmas.

b. Studi Literatur

Penulis mencari referensi yang berkaitan dengan Algoritma Floyd-Warshall dan aplikasi berbasis Web-Gis dengan penerapan algoritma yang sama.

\subsection{Metode Pengembangan Sistem}

a. Analisa sistem

Untuk mempermudah dalam proses perancangan sistem, maka diperlukan analisis sebelum melakukan proses selanjutnya.

b. Perancangan Sistem

Setelah dilakukan analisis dalam pengembangan sistem, maka diperlukan suatu perancangan sistem yaitu menggunakan Data Flow Diagram (DFD).

c. Implementasi Sistem

Langkah pembuatan program yaitu menampilkan peta Kabupaten Karanganyar terlebih dahulu menggunakan Google Maps Api, menentukan titik koordinat puskesmas (latitude dan longitude), kemudian menerapkan algoritma Floyd-Warshall untuk penentuan jalur terpendek puskesmas di Kabupaten Karanganyar.

d. Pengujian Sistem

Pada tahap pengujian sistem dilakukan dengan 2 tahap, yaitu: pengujian fungsional yang digunakan untuk menguji fungsi menu yang terdapat di dalam aplikasi, dan pengujian validitas yang digunakan untuk mengetahui jalur valid atau tidak.

\section{HASIL DAN PEMBAHASAN}

\subsection{Analisa Sistem}

Kabupaten Karanganyar adalah wilayah geografis di Jawa Tengah. Kabupaten Karanganyar mempunyai 21 puskesmas. Puskesmas mempunyai tugas menyelenggarakan urusan daerah di bidang kesehatan. Dalam aplikasi yang nanti akan dibuat berkaitan dengan sarana kesehatan yaitu pencarian jalur terpendek puskesmas di Kabupaten Karanganyar. 
Penentuan jalur terpendek dengan Algoritma Floyd-Warshall digunakan untuk menentukan jarak terpendek antara semua pasang titik dalam suatu graf berbobot di mana titiktitiknya saling berhubungan (Ammar \& Suprapto, 2015). Peta yang diperoleh ditransformasikan ke dalam bentuk graf serta diberi bobot sesuai jarak hasil pengukuran dari satu titik ke titik yang lain. Gambar 2 merupakan contoh graf dari Kantor Kepala Desa Nglebak menuju UPT Puskesmas Tawangmangu. Hal ini digunakan sebagai gambaran perhitungan algoritma FloydWarshal pada titik awal Kantor Kepala Desa Nglebak dan titik tujuan UPT Puskesmas Tawangmangu.

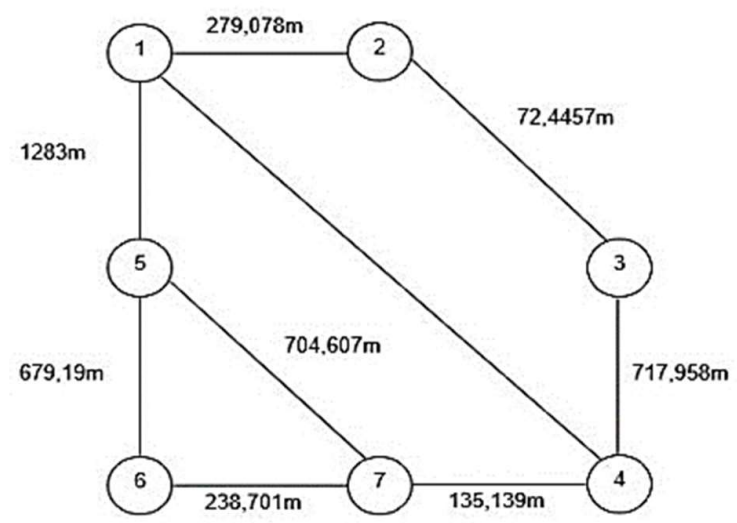

Gambar 2. Graf Jalur Puskesmas 1 Menuju 7

Keterangan pada Gambar 2, adalah sebagai berikut.

m (meter) : satuan jarak antar objek

$\begin{array}{ll}1 & : \text { Kantor Kepala Desa Nglebak (Start Point) } \\ 2 & : \text { Jl. Krangean } \\ 3 & : \text { Jl. Pringgosari } \\ 4 & : \text { Jl. Grojogan Sewu } \\ 5 & : \text { Jl. Srikaton } \\ 6 & : \text { Jl. Lawu - Jl. Grojogan Sewu } \\ 7 & : \text { UPT Puskesmas Tawangmangu (End Point) }\end{array}$

Dari graf yang telah digambarkan ada beberapa jalur yang bisa dilalui serta bobot dari satu node ke node lain, dan kita akan menentukan rute terpendek yang dapat dilalui menggunakan algoritma Floyd-Warshall (Nugraha, Amriana, \& Arif, 2020). Berdasarkan persamaan (2.1), diperoleh uraian penyelesaian sebagai berikut.

Iterasi 1 : Untuk iterasi ini $P=\{1\}$ dengan $P_{l}=0$ dan $t_{j}=q_{i j}, j=2,3, \ldots, 7$. Dengan memeriksa gambar 4.2, sisi dari 1 ke 2 mempunyai bobot $279,078 \mathrm{~m}$ sehingga $t_{2}$ $=279,078 \mathrm{~m}$ dan seterusnya. Karena tidak ada sisi dari $1 \mathrm{ke} 4$, maka isi $t_{4}=\infty$ dan seterusnya. Jadi, $t_{2}=279,078 \mathrm{~m}, t_{3}=\infty, t_{4}=\infty, t_{5}=1283 \mathrm{~m}, t_{6}=\infty, t_{7}=\infty$.

Langkah 1 : Perhatikan bahwa $t_{j}$ minimum untuk $j=5$. Oleh karena itu, kita masukkan 5 ke $P$ sehingga $P=\{1,5\}$. Kita labeli busur $(1,5)$.

Langkah 2 : Dari langkah $1, P=\{1,5\}$ dan $t_{5}=1283 \mathrm{~m}$ sehingga dapat diperoleh $t_{2}=\min \left\{t_{2}, t_{5}+q_{52}\right\}=\min \{279,078,1283+\infty\}=279,078 \mathrm{~m}$. $t_{3}=\min \left\{t_{3}, t_{5}+q_{53}\right\}=\min \{\infty, 1283+\infty\}=\infty$. 


$$
\begin{aligned}
& t_{4}=\min \left\{t_{4}, t_{5}+q_{54}\right\}=\min \{\infty, 1283+\infty\}=\infty . \\
& t_{6}=\min \left\{t_{6}, t_{5}+q_{56}\right\}=\min \{\infty, 1283+679,19\}=1962,19 \mathrm{~m} . \\
& t_{7}=\min \left\{t_{7}, t_{5}+q_{57}\right\}=\min \{\infty, 1283+704,607\}=1987,607 \mathrm{~m} .
\end{aligned}
$$

Iterasi 2 : Untuk iterasi ini $P=\{1,5\}$ dan $P_{1}=0, P_{2}=t_{2}=279,078 \mathrm{~m}$, juga $t_{3}=\infty, t_{4}=\infty, t_{6}$ $=1962,19 \mathrm{~m}, t_{7}=1987,607 \mathrm{~m}$.

Langkah 1 : Perhatikan bahwa untuk $t_{j}, j<5$, minimum untuk $j=2$. Oleh karena itu, kita masukkan 2 ke $P$ sehingga $P=\{1,5,2\}$. Kita labeli busur $(5,2)$.

Langkah 2 : Dari langkah $1, P=\{1,5,2\}$ dan $t_{5}=1283 \mathrm{~m}$ dan $t_{2}=279,078 \mathrm{~m}$ sehingga dapat diperoleh

$$
\begin{aligned}
& t_{3}=\min \left\{t_{3}, t_{2}+q_{23}\right\}=\min \{\infty, 279,078+72,4457\}=351,5237 \mathrm{~m} . \\
& t_{4}=\min \left\{t_{4}, t_{2}+q_{24}\right\}=\min \{\infty, 279,078+\infty\}=\infty \\
& t_{5}=\min \left\{t_{5}, t_{2}+q_{25}\right\}=\min \{\infty, 279,078+\infty\}=\infty \\
& t_{6}=\min \left\{t_{6}, t_{2}+q_{26}\right\}=\min \{\infty, 279,078+\infty\}=\infty \\
& t_{7}=\min \left\{t_{7}, t_{2}+q_{27}\right\}=\min \{\infty, 279,078+\infty\}=\infty
\end{aligned}
$$

Iterasi 3 : Untuk iterasi ini $P=\{1,5,2\}$ dan $P_{1}=0, P_{2}=t_{2}=279,078 \mathrm{~m}$, juga $t_{3}=351,5237 \mathrm{~m}$, $t_{4}=\infty, t_{5}=\infty, t_{6}=\infty, t_{7}=\infty$.

Langkah 1: Perhatikan bahwa untuk $t_{j}, j>2$, minimum untuk $j=3$. Oleh karena itu, kita masukkan 3 ke $P$ sehingga $P=\{1,5,2,3\}$. Kita labeli busur $(2,3)$.

Langkah 2 : Dari langkah $1, P=\{1,5,2,3\}$ dan $t_{2}=279,078 \mathrm{~m}, t_{3}=351,5237$ sehingga dapat diperoleh

$$
\begin{aligned}
& t_{4}=\min \left\{t_{4}, t_{3}+q_{34}\right\}=\min \{\infty, 351,5237+717,958\}=1069,4817 \mathrm{~m} . \\
& t_{5}=\min \left\{t_{5}, t_{3}+q_{35}\right\}=\min \{\infty, 351,5237+\infty\}=\infty . \\
& t_{6}=\min \left\{t_{6}, t_{3}+q_{36}\right\}=\min \{\infty, 351,5237+\infty\}=\infty . \\
& t_{7}=\min \left\{t_{7}, t_{3}+q_{37}\right\}=\min \{\infty, 351,5237+\infty\}=\infty .
\end{aligned}
$$

Iterasi 4 : Untuk iterasi ini $P=\{1,5,2,3\}$ dan $P_{1}=0, P_{2}=t_{2}=279,078 \mathrm{~m}$, juga $t_{3}=$ $351,5237 \mathrm{~m}, t_{4}=1069,4817 \mathrm{~m}, t_{5}=\infty, t_{6}=\infty, t_{7}=\infty$.

Langkah 1 : Perhatikan bahwa untuk $t_{j}, j>3$, minimum untuk $j=4$. Oleh karena itu, kita masukkan 4 ke $P$, sehingga $P=\{1,5,2,3,4\}$. Kita labeli busur $(3,4)$.

Langkah 2 : Dari langkah $1, P=\{1,5,2,3,4\}$ dan $t_{3}=351,5237 \mathrm{~m}, t_{4}=1069,4817 \mathrm{~m}$ sehingga dapat diperoleh

$$
\begin{aligned}
& t_{5}=\min \left\{t_{5}, t_{4}+q_{45}\right\}=\min \{\infty, 1069,4817+\infty\}=\infty . \\
& t_{6}=\min \left\{t_{6}, t_{4}+q_{46}\right\}=\min \{\infty, 1069,4817 \mathrm{~m}+\infty\}=\infty . \\
& t_{7}=\min \left\{t_{7}, t_{4}+q_{47}\right\}=\min \{\infty, 1069,4817+135,139\}=1204,6207 \mathrm{~m} .
\end{aligned}
$$

Iterasi 5 : Untuk iterasi ini $P=\{1,5,2,3,4\}$ dan $P_{1}=0, P_{2}=t_{2}=279,078 \mathrm{~m}$, juga $t_{3}=$ $351,5237 \mathrm{~m}, t_{4}=1069,4817 \mathrm{~m}, t_{5}=\infty, t_{6}=\infty, t_{7}=1204,6207 \mathrm{~m}$.

Langkah 1 : Perhatikan bahwa untuk $t_{j}, j>4$, minimum untuk $j=7$. Oleh karena itu, kita masukkan 7 ke $P$ sehingga $P=\{1,5,2,3,4,7\}$. Kita labeli busur $(4,7)$.

Langkah $2:$ Kita mempunyai $P=\{1,5,2,3,4,7\}$ dan $P_{1}=0, P_{2}=t_{2}=279,078 \mathrm{~m}$, juga $t_{3}=$ $351,5237 \mathrm{~m}, t_{4}=1069,4817 \mathrm{~m}, t_{5}=\infty, t_{6}=\infty, t_{7}=1204,6207 \mathrm{~m}$. merupakan himpunan titik, Proses kita hentikan. Karena pada node 5 tidak ada jalur menuju 2 atau pada node 5 harus berbalik ke node 1 maka diambil kesimpulan node 5 mempunyai jalur yang lebih panjang dari pada node 1 ke node 2 secara langsung. Jadi, jarak terpendek dari titik 1 ke 7 adalah $1+2+3+4+7=1204,6207 \mathrm{~m}$.

Lintasan terpendeknya adalah : 1 -- 2 -- 3 -- 4 -- 7. 
Tabel 1. Hasil Graf 1 Menuju 7

\begin{tabular}{cccccccc}
\hline ID & 1 & 2 & 3 & 4 & 5 & 6 & 7 \\
\hline 1 & 0 & 279,078 & 0 & 0 & 1283 & 0 & 0 \\
2 & 0 & 0 & 351,5237 & 0 & 0 & 0 & 0 \\
3 & 0 & 0 & 0 & 1069,4817 & 0 & 0 & 0 \\
4 & 0 & 0 & 0 & 0 & 0 & 0 & 1204,6207 \\
5 & 0 & 0 & 0 & 0 & 0 & 1962,19 & 1987,607 \\
6 & 0 & 0 & 0 & 0 & 0 & 0 & 0 \\
7 & 0 & 0 & 0 & 0 & 0 & 0 & 0 \\
\hline
\end{tabular}

\subsection{Perancangan Sistem}

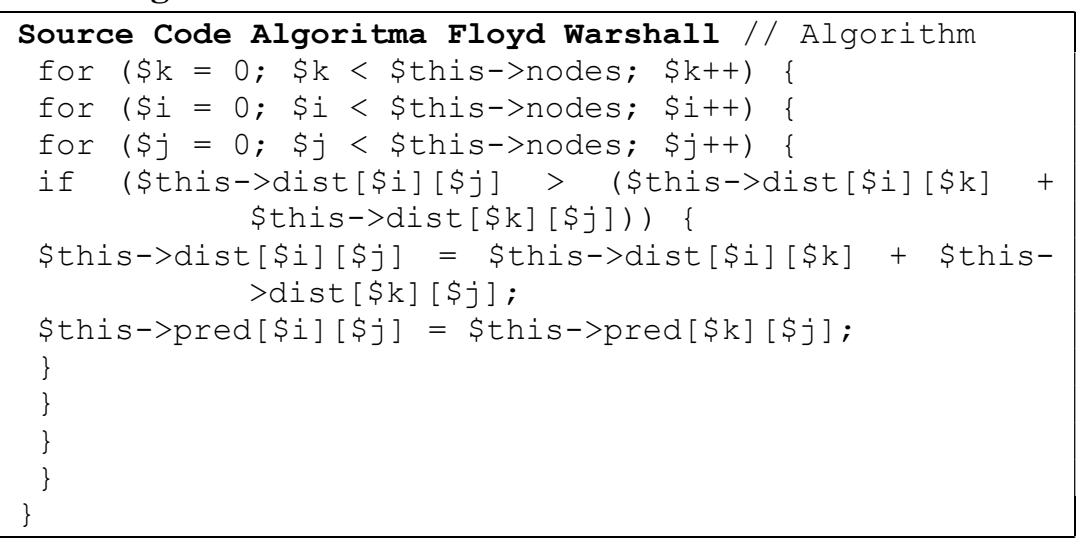

Diagram konteks yang terjadi pada Gambar 3 adalah hubungan antara Admin dengan Aplikasi Geografis dan User. Gambar 4, diagram alir DFD yang diambil pada level 0. Proses terdiri dari tiga bagian, diantaranya pengolahan data tempat, pengolahan kalkulasi algoritma Floyd Warshall, dan Output.

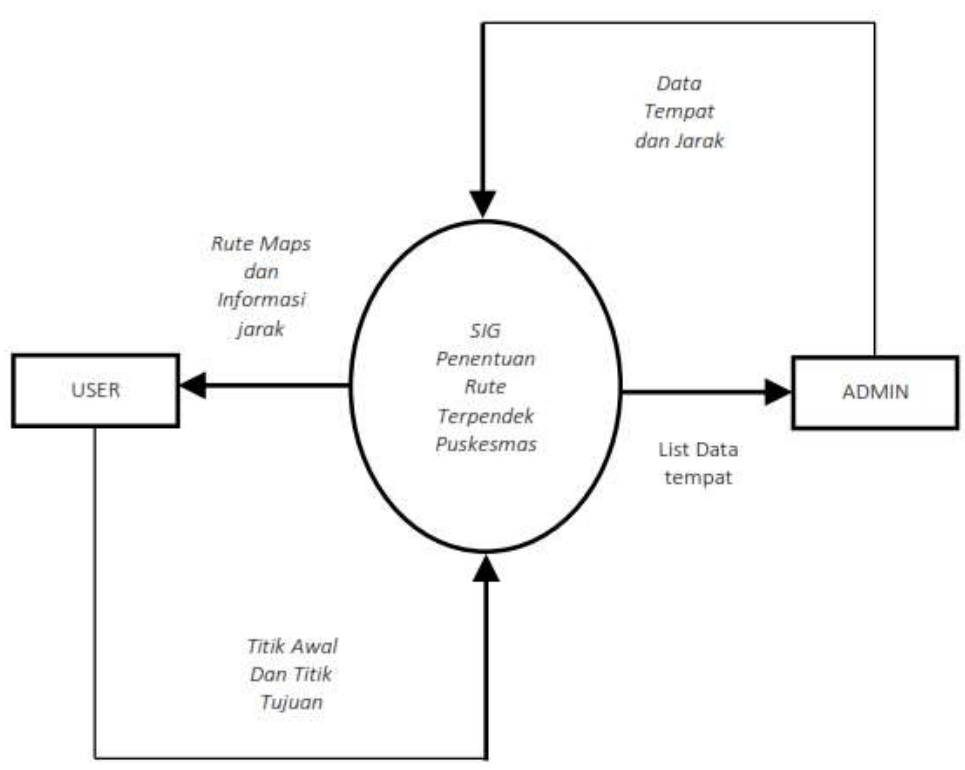

Gambar 3. Diagram Konteks 


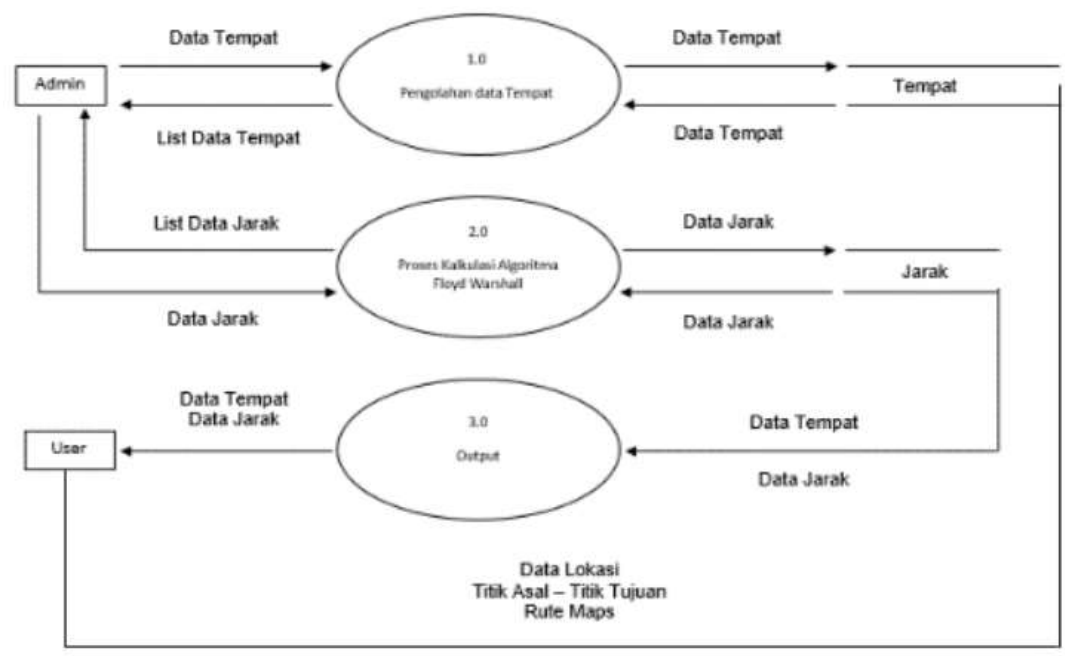

Gambar 4. DFD Level 0

\subsection{Implementasi Sistem}

\section{Implementasi Rute}

Pada pengujian ini, akan ditentukan rute terpendek yang akan dipilih algoritma FloydWarshall. User memilih titik asal dan titik tujuan. Titik asal yang tersedia yaitu titik umum dan puskesmas, untuk titik tujuan yaitu puskesmas di Kabupaten Karanganyar ditunjukkan pada Gambar 5.
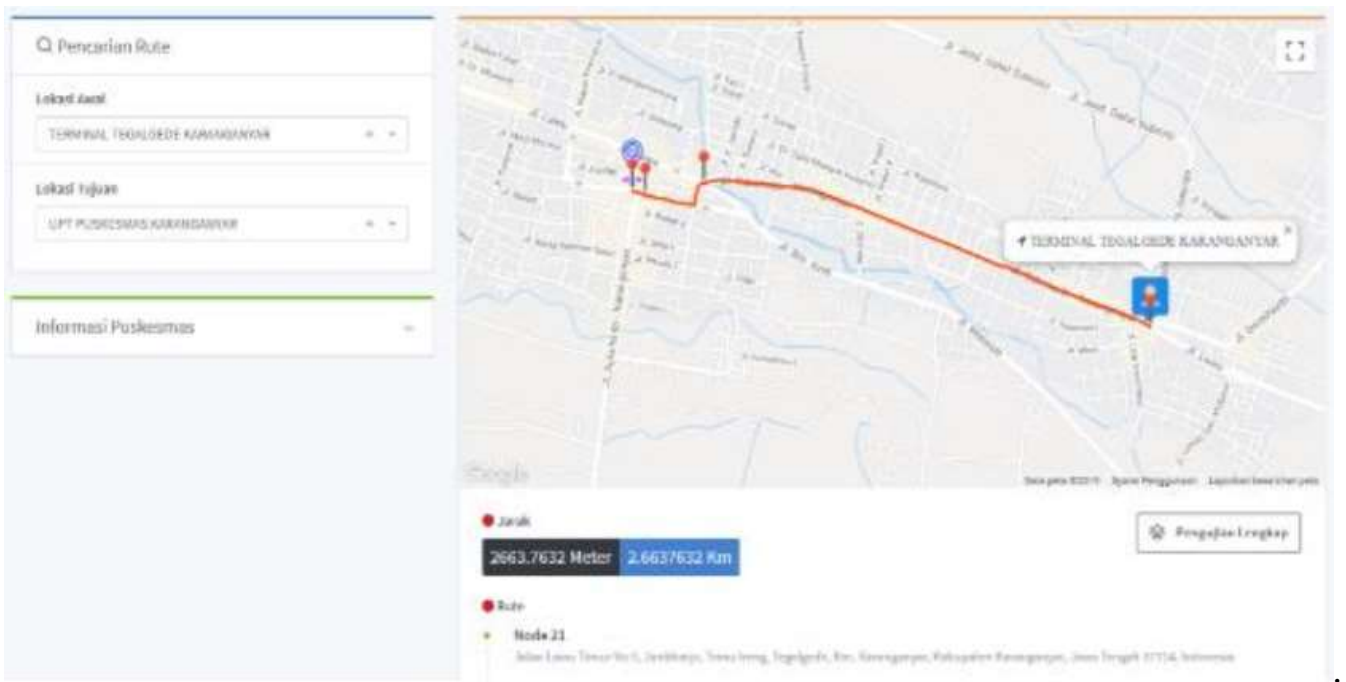

Gambar 5. Implementasi Rute

\section{Implementasi Informasi Lokasi}

Pada pengujian Informasi Lokasi, akan ditunjukkan informasi-informasi lokasi Puskesmas yang tercantum. User mengeklik Pin Merah kecil yang ada pada peta, maka otomatis menunjukkan data-data dari Lokasi Puskesmas yang ada seperti ditunjukkan pada Gambar 6 . 


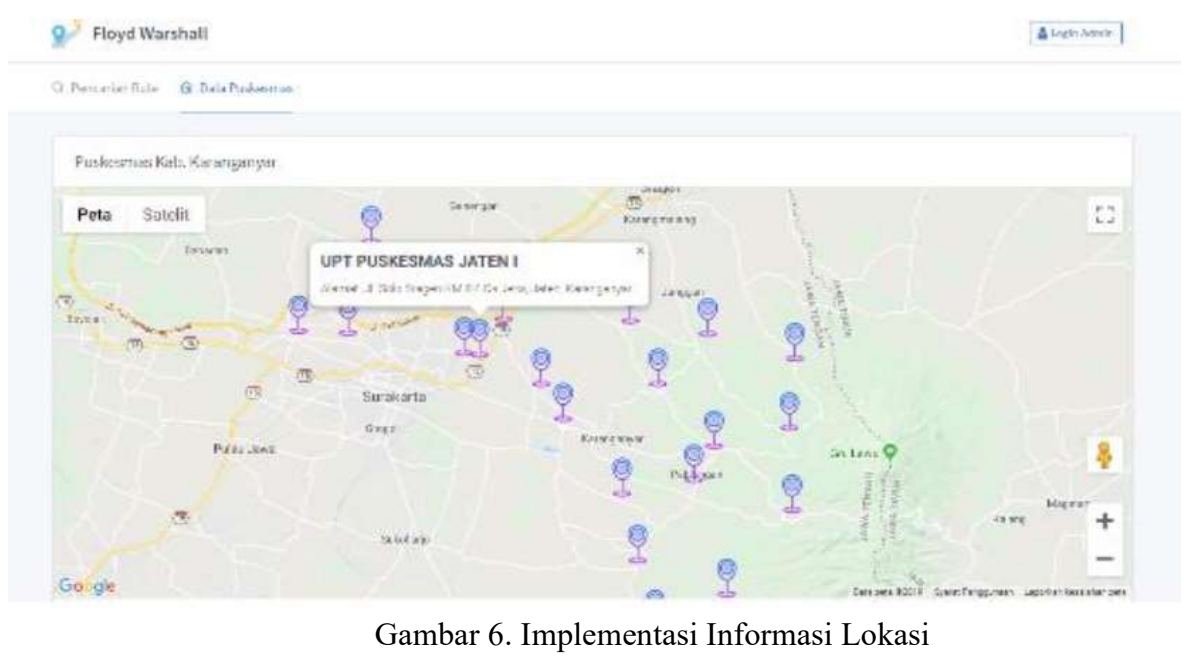

\subsection{Pengujian Sistem}

\section{Pengujian Fungsional}

Pengujian fungsional merupakan teknik pengujian yang digunakan untuk menguji fitur atau fungsi dari sistem perangkat lunak, harus mencakup semua skenario dan kesimpulan (Cholifah, Yulianingsih, \& Sagita, 2018). Berikut adalah hasil dari pengujian fungsional. pengujian sistem ditunjukkan pada Tabel 2 .

Tabel 2. Pengujian fungsional

\begin{tabular}{|c|c|c|c|}
\hline Komponen & Skenario Pengujian & Pengamatan & Kesimpulan \\
\hline Pengujian Rute & $\begin{array}{l}\text { Menampilkan hasil rute } \\
\text { terpendek yang ditampilkan } \\
\text { dalam bentuk variabel sesuai } \\
\text { dengan titik-titik yang muncul } \\
\text { pada peta. }\end{array}$ & $\begin{array}{l}\text { Data didapat dengan } \\
\text { mengeklik lokasi awal, } \\
\text { lalu lokasi tujuan. Hasil } \\
\text { menunjukkan jalur } \\
\text { terdekat dapat ditampilkan. }\end{array}$ & Sesuai \\
\hline $\begin{array}{l}\text { Pengujian Informasi } \\
\text { Lokasi }\end{array}$ & $\begin{array}{l}\text { Menampilkan data dari Lokasi } \\
\text { Puskesmas yang tercantum. }\end{array}$ & $\begin{array}{l}\text { Hasil yang ditampilkan } \\
\text { adalah informasi-informasi } \\
\text { dari Lokasi Puskesmas, } \\
\text { diantaranya alamat lokasi, } \\
\text { serta nomor telepon }\end{array}$ & Sesuai \\
\hline Pengujian Login & $\begin{array}{l}\text { Memasukkan username dan } \\
\text { passord untuk masuk ke } \\
\text { halaman admin }\end{array}$ & $\begin{array}{l}\text { Ketika username dan } \\
\text { password sesuai maka } \\
\text { akan masuk ke halaman } \\
\text { admin }\end{array}$ & Sesuai \\
\hline
\end{tabular}

\section{Pengujian Validitas}

Pengujian Validitas digunakan untuk mengetahui apakah hasil dari aplikasi program menunjukkan kesesuaian atau tidak dengan hasil perhitungan manual (Sugiharni, 2018). Hasil perhitungan program dapat ditunjukkan pada Gambar 7. 


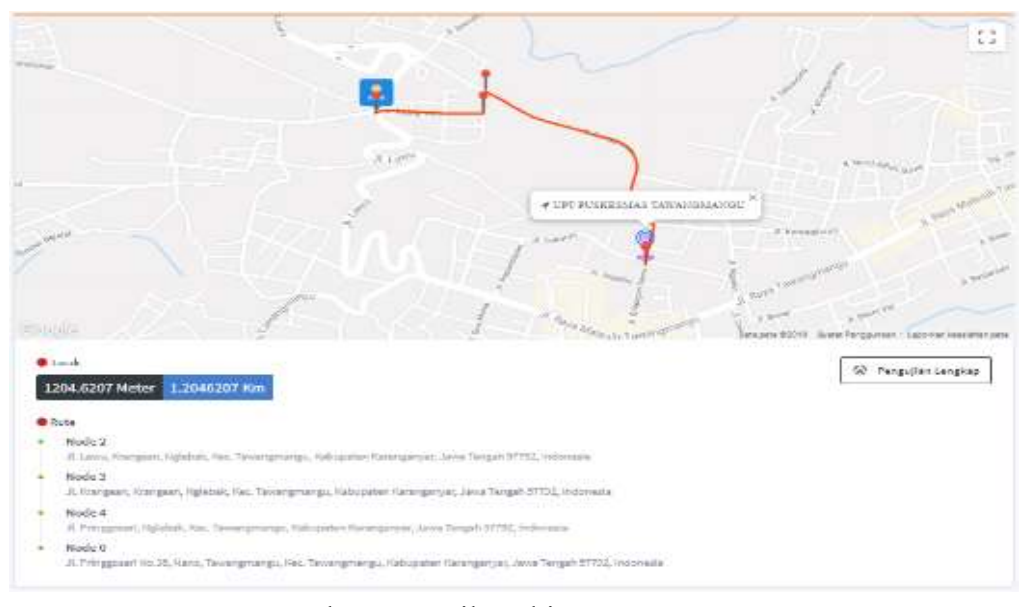

Gambar 7. Hasil Perhitungan Program

Selanjutnya, akan dilakukan perbandingan dengan hasil perhitungan manual dan hasil survei menggunakan kendaraan. Hal ini dapat dilihat pada Tabel 3. Berdasarkan Tabel 3 terdapat beberapa faktor dalam perbandingan sistem lama dan sistem baru yaitu faktor kinerja, informasi, dan efisiensi.

Tabel 3. Hasil Uji Validitas

\begin{tabular}{cll}
\hline Faktor & \multicolumn{1}{c}{ Validitas Sistem Lama } & \multicolumn{1}{c}{ Validitas Sistem Baru } \\
\hline Kinerja & $\begin{array}{l}\text { Di Dinas Kesehatan Kabupaten } \\
\text { Karanganyar Belum ada aplikasi sistem } \\
\text { informasi geografis puskesmas Se- } \\
\text { Kabupaten Karanganyar }\end{array}$ & $\begin{array}{l}\text { Masyarakat akan mudah mengakses sistem } \\
\text { informasi geografis puskesmas yang terdapat } \\
\text { di Kabupaten Karanganyar. }\end{array}$ \\
Informasi & $\begin{array}{l}\text { Masyarakat tidak bisa mengetahui secara } \\
\text { detail jalur yang dilalui menuju } \\
\text { puskesmas tersebut. }\end{array}$ & $\begin{array}{l}\text { Masyarakat pendatang diluar wilayah } \\
\text { Kabupaten Karanganyar bisa mengetahui } \\
\text { secara detail jalur yang dilalui menuju } \\
\text { Puskesmas. }\end{array}$ \\
& $\begin{array}{l}\text { Efisien sekali, karena jalur dapat dilihat } \\
\text { Efisiensi }\end{array}$ & $\begin{array}{l}\text { Tidak efisien karena membuang waktu } \\
\text { untuk koreksi. }\end{array}$ \\
\hline
\end{tabular}

\section{SIMPULAN}

Berdasarkan analisis dan implementasi sistem penentuan rute terpendek Lokasi Puskesmas yang dilakukan oleh peneliti, maka dapat diambil beberapa kesimpulan sebagai berikut. Dalam proses penelitian ini berhasil membuat aplikasi penentuan rute terpendek lokasi puskesmas di Kabupaten Karanganyar menggunakan Algoritma Floyd-Warshall berbasis Sistem Informasi Geografis sebagai bahan pertimbangan pencarian rute terpendek oleh User. Aplikasi penentuan rute terpendek Lokasi Puskesmas ini masih dalam tahap pengembangan agar kinerja sistem semakin baik. Oleh karena itu disarankan beberapa hal sebagai berikut Sistem dapat ditambahkan petunjuk jalan dan informasi tentang jalan yang akan dilalui. Sistem dapat dikembangkan di sistem operasi open source seperti android agar mudah diakses oleh User. Sistem dapat dikembangkan dengan menambahkan kriteria waktu tempuh dan informasi kepadatan jalan saat pagi, siang, dan malam hari. 


\section{DAFTAR PUSTAKA}

Ammar, C., \& Suprapto, H. (2015). Penerapan Algoritma Floyd Warshall dalam Pencarian Rute Terpendek dan Tercepat pada Studi Kasus di Singapura Hingga Thailand Selatan berbasis Android. Jurnal Ilmiah Informatika Dan Komputer, 20(2), 85-100.

Anisiyah, W., Agus, F., \& Hamdani. (2011). Penentuan Rute Terpendek Menuju Pusat Kesehatan Menggunakan Metode Dijkstra berbasis Web-GIS. Jurnal Informatika Mulawarman, 6(3), 126-131.

Bellina, B. (2017). Kualitas Pelayanan Kesehatan oleh Puskesmas di Kecamatan Parigi Kabupaten Pangandaran. Moderat: Jurnal Ilmiah Ilmu Pemerintahan, 3(3), 115-125.

Cholifah, W. N., Yulianingsih, \& Sagita, S. M. (2018). Pengujian Black Box Testing pada Aplikasi Action dan Strategi berbasis Android dengan Teknologi Phonegap. Jurnal String, 3(2), 206-210.

Daniel, F., Prida, \& Tadeo, L. (2019). Teori Graf. Yogyakarta: Deepublish.

Darnita, Y., Toyib, R., \& Rinaldi. (2017). Implementasi Algoritma Floyd Warshall untuk Menentukan Letak dan Lokasi Perusahaan Travel/Rental Mobil di Kota Bengkulu. Jurnal Pseudocode, 4(2), 144-156.

Konli, S. (2014). Pelayanan Kesehatan Masyarakat di Puskesmas Desa Gunawan Kecamatan Sesayap Kab Tana Tidung. eJoournal Ilmu Pemerintahan, 2(1), 10-15.

Marsudi. (2016). Teori Graf. Malang: Universitas Brawijaya Press.

Nugraha, D. W., Amriana, \& Arif, A. (2020). Implementasi Algoritma Floyd Warshall pada Pencarian Lokasi Agen Bus, Tour Travel, dan Rental Mobil berbasis Android. Jurnal Sains, Aplikasi, Komputasi Dan Teknologi Informasi, 2(2), 41-51.

Sugiharni, G. A. D. (2018). Pengujian Validitas Konten Media Pembelajaran Interaktif Berorientasi Model Creative Problem Solving. Jurnal Penelitian Dan Pengembangan Pendidikan, 2(2), 88-95. 